\title{
LES POLÍTIQUES D’ADAPTACIÓ AL CANVI CLIMÀTIC A CATALUNYA
}

\author{
GABRIEL BORRÀS CALVO \\ Oficina Catalana del Canvi Climàtic \\ gborras@gencat.cat
}

Rebut: 14 de març de 2013 / Acceptat: 1 de juliol de 2013

RESUM: A les portes de què el Panell Intergovernamental del Canvi Climàtic (IPCC) comenci a publicar el setembre d'enguany els resultats del cinquè informe sobre el canvi climàtic, aquesta nota fa un repàs a les polítiques d'adaptació que s'han dut a terme tant a nivell internacional com, particularment, a Catalunya. La finalitat és fixar l'estat de la qüestió en quest àmbit

RESUMEN: A las puertas de que el Panel Intergubernamental del Cambio Climático (IPCC) empiece a publicar en septiembre de este año los resultados del quinto informe sobre el cambio climático, esta nota repasa las políticas de adaptación que se han llevado a cabo tanto a nivel internacional como, particularmente, en Catalunya. La finalidad es hacer un estado de la cuestión en este ámbito.

ABSTRACT: When the Intergovernmental Panel on Climate Change (IPCC) is in the verge of publishing the results of the fifth report on climate change next September, this note aims to give the current status regarding this issue, at international level as well as in Catalonia.

PARAULES CLAU: Canvi climàtic — Impactes — Adaptació.

PALABRAS CLAVE: Cambio climático — Impactos — Adaptación. 
KEY WORDS: Climate Change - Impacts - Adaptation.

Sumari: I. Introducció. II. Antecedents immediats al món, Europa i Espanya. 1. Al món. 2. A Europa. 3. A Espanya. III. Antecedents i situació a Catalunya: l'aprovació de l'estratègia catalana d'adaptació i la Llei de canvi climàtic.

\section{INTRODUCCIÓ}

El clima del planeta és en un procés de canvi que ha comportat i comportarà impactes positius i negatius sobre diversos sectors socioeconòmics i sistemes naturals del món. La comunitat científica internacional alerta de la necessitat de mantenir la temperatura global del planeta per sota de l'increment dels $2^{\circ} \mathrm{C}$ des de l'era preindustrial. Per aconseguir-ho és necessari l'establiment de reduccions significatives de les emissions de gasos amb efecte d'hivernacle. En cas que aquestes reduccions no s'assoleixin, caldrà destinar més esforços a l'adaptació dels impactes i, en conseqüència, majors costos. D'acord amb l'informe Stern ${ }^{1}$ cal una inversió equivalent a 1'1\% del PIB mundial per a poder esmorteir els efectes del canvi climàtic i, si no s'executa aquesta inversió, el món sencer s'exposaria a una recessió que podria arribar a suposar el $20 \%$ del PIB del planeta. Per això, el Govern de la Generalitat de Catalunya, conscient del repte que suposa i suposaran els impactes del canvi climàtic, ha aprovat l'Estratègia Catalana d'Adaptació al Canvi Climàtic 2013-2020 (ESCACC, vegeu capítol 3)².

En el seu últim informe presentat el 2007, el Panell Intergovernamental del Canvi Climàtic $(\text { IPCC })^{3}$ ha determinat que l'origen de l'escalfament global i del conseqüent canvi climàtic, ja inqüestionable, és fonamentalment antròpic. Redactat i/o avalat per la més àmplia comunitat científica internacional $\mathrm{i}$, independentment del llenguatge més $o$ menys tècnic utilitzat i sovint expressat en termes de probabilitats o nivells d'incertesa, el que es reconeix amb aquest informe suposa un important pas respecte informes anteriors, en confirmar l'origen antropogènic de les causes del canvi climàtic a través de l'emissió de gasos amb efecte d'hivernacle (GEH).

\footnotetext{
1 Informe Stern. Disponible a: <http://webarchive.nationalarchives.gov.uk/+/http://www.hmtreasury.gov.uk/media/2/9/stern_shortsummary_spanish.pdf $>$.

${ }^{2}$ L'Estratègia Catalana d'Adaptació al Canvi Climàtic (Horitzó 2013-2020, ESCACC) va ser aprovada pel Govern de la Generalitat de Catalunya, el 13 de novembre de 2012. El document d'aquesta Estratègia es pot consultar a: <http://www20.gencat.cat/docs/canviclimatic/Home/Actualitat/docs/ESCACC.pdf>.

${ }^{3}<$ http://www.ipcc.ch/publications_and_data/ar4/syr/en/contents.html>.
} 
El canvi climàtic, però, només és un indicador de l'anomenat canvi global, el procés que s'està produint arreu com a conseqüència de la intensa modificació de les condicions naturals dels ecosistemes, fruit d'un creixement sense precedents al llarg de tot el passat i present segle (ja som 7.000 milions d'habitants) i un desenvolupament extrem en tots els camps: la generació d’energia, la gestió agrícola i forestal, la urbanització, la sobreexplotació hídrica, etc. Un canvi global que comporta, entre d'altres, la desruralització de les societats, la concentració de la població en grans urbs, els moviments migratoris, la globalització de la comunicació i del coneixement i, sobretot, un canvi global producte d'una economia basada, en els darrers decennis, en la concepció que els recursos naturals són gratuïts i infinits i, per tant, depredables eternament; una economia que si bé ha millorat les condicions de vida d'una part de la població mundial, no ha estat capaç de resoldre el problema de l'equitat i l'accés als serveis bàsics.

Aquests canvis, o els seus efectes, es manifesten en diferents sistemes naturals o físics (costes, deltes, mars, aigua dolça, boscos, serralades, geleres) i en diversos sectors socioeconòmics (agricultura, turisme, energia, gestió forestal, protecció civil, gestió de l'aigua, salut, pesca). En general, es pot dir que les estratègies per afrontar els impactes del canvi climàtic en els sistemes $i$ en els sectors passen per la diagnosi dels seus impactes, la mitigació de les seves causes i l'adaptació a les condicions futures. De fet, les estratègies d'adaptació a les noves i/o actuals condicions del canvi climàtic requereixen, primer, desenvolupar una diagnosi el més detallada i fiable possible sobre quines seran les condicions futures de referència. En el cas que ens toca, aquestes condicions cal referir-les a escala nacional de Catalunya. Aquest és precisament un dels objectius de l'Estratègia Catalana d'Adaptació al Canvi Climàtic (ESCACC): determinar amb el major detall possible els impactes que el canvi climàtic produirà i/o està produint en els diversos sistemes $\mathrm{i}$ sectors en totes les seves dimensions a Catalunya d'acord amb el millor estat del coneixement actualment disponible. En conseqüència, i aquesta és una de les raons del per què cal bastir una estratègia i no pas un pla, és menester afavorir l'impuls en la recerca de simulacions d'escenaris regionals per tal de reduir la incertesa en la projecció de l'evolució dels indicadors climàtics (temperatura, precipitació, vent, humitat, ascens del nivell del mar, circulació marina, etc.) al nostre país i, així, delimitar millor els impactes i les vulnerabilitats. Una de les principals fonts d'incertesa de les simulacions d'escenaris regionals de canvi climàtic 
resideix en la definició dels anomenats escenaris d'emissions, que reflecteixen diferents concentracions a l'atmosfera de gasos amb efecte d'hivernacle segons l'evolució socioeconòmica arreu del planeta durant les properes dècades. Cal tenir present que la situació global actual sembla dirigir-se cap als escenaris de majors nivells d'emissions d'acord amb les últimes mesures preses per l'observatori de Mauna Loa ${ }^{4}$ que situa en 400 parts per milió la concentració de diòxid de carboni a l'atmosfera, ben lluny dels 280 ppm de l'era preindustrial.

La pròpia modelització climàtica també presenta incerteses destacades, en part intrínseques als models, en part degudes al coneixement només parcial de certs processos fisicoquímics que intervénen en el sistema climàtic (manca de coneixement complet del cicle del carboni, de la dinàmica de les escorces de gel, etc.) i en part associades a limitacions actuals de càlcul, que van millorant paulatinament. Dels models climàtics globals disponibles al món, s'han desenvolupat nombrosos models climàtics regionals que, aplicats en àmbits menors a partir de l'aniuament sobre els globals, ofereixen resultats més particulars i de major detall espacial, tot i que amb importants diferències entre uns i altres. Actualment s'avança en la integració d'aquests diferents models regionals, amb diferents escenaris i diferents tècniques estadístiques de regionalització, a la vegada que es progressa directament en ampliar la capacitat dels models globals amb nous simuladors cada vegada més potents que amplien la resolució dels càlculs realitzats fins ara pràcticament al nivell dels models regionals actuals; d'aquí la importància del conveni signat entre el Servei Meteorològic de Catalunya i el Centre de Supercomputació per a l'ús del superordinador Mare Nostrum per a la generació d'escenaris climàtics regionalitzats a Catalunya durant el segle XXI (projecte "ESCAT”, vegeu capítol 3) 5 .

El canvi climàtic com a tal ja ningú no el qüestiona. Fins i tot, des d'instàncies negacionistes i escèptiques -convençuts bé sigui de què no hi ha relació entre l'activitat antròpica i l'escalfament del planeta, bé sigui de què en realitat aquest escalfament no és tal- s'han afanyat amb rapidesa a pujar al tren de l'adaptació al canvi climàtic perquè hi veuen una seriosa i àmplia oportunitat de negoci. Una dada: la Xarxa d'Inversors en

\footnotetext{
${ }^{4}<$ http://www.treehugger.com/climate-change/10-nasa-scientists-speak-400-ppm-co2-milestone.html>. 
Risc Climàtic dels Estats Units (INCR en anglès) ${ }^{6}$, la Institució Europea del Grup d'Inversors en Canvi Climàtic (IIGCC en anglès) i l'homònim europeu d'Austràlia i Nova Zelanda, i que reuneixen un grup de 285 inversors que representen més de 20 mil milions de dòlars en actius, van adreçar el 19 d'octubre de 2011 una carta als governs del G20 on reclamen majors inversions en accions de lluita contra el canvi climàtic i en favor de l'adaptació.

Una enquesta publicada al número 127 de la "Revista Economistas" el maig de 2011 i realitzada per Xavier Labandeira, catedràtic d'economia de la Universitat de Vigo ${ }^{7}$, demostra que el $77,3 \%$ dels ciutadans de l'Estat espanyol manifesten que el canvi climàtic és un fenomen real i no exagerat, mentre que un $87,6 \%$ creu que cal aplicar polítiques correctores. Per polítiques correctores s'entenen bàsicament aquelles orientades a la reducció de gasos amb efecte d'hivernacle $(\mathrm{GEH})$ atès que el coneixement general sobre què és l'adaptació i les mesures d'adaptació al canvi climàtic és força inexistent, per no dir nul, entre la majoria de la població; només algunes entitats i organismes especialitzats en la recerca i innovació en els sistemes naturals i determinats sectors (biodiversitat, innovació agroramadera, sector vitivinícola, gestió de l'aigua i gestió forestal) disposen de coneixement sobre l'adaptació. Unes mesures d'adaptació que cal identificar i impulsar perquè Catalunya ja ha constatat l'augment de la variabilitat climàtica: l'increment de temperatura ha estat d'uns $0,24{ }^{\circ} \mathrm{C}$ per dècada de per al període $1950-2011^{8}$, de forma més acusada a l'estiu i per a les temperatures màximes diàries. Els canvis sobre les precipitacions, però, són molt més difícils d'establir o constatar de forma clara, especialment en el nostre àmbit mediterrani de gran variabilitat pluviomètrica estacional i interanual, a més de la seva característica distribució espacial irregular. Tanmateix, per al període 1950-2011, s'ha observat una reducció de la precipitació a l'estiu del 5,4\% per dècada. Recentment, la Societat Americana de Meteorologia s'ha fet ressò d'un estudi (“'On the Increased Frequency of Mediterraean Drought”, NOAA Earth System Research Laboratory, Journal of Climate

\footnotetext{
6 Xarxa d'Inversors en Risc Climàtic dels Estats Units. Disponible a: $<$ http://investorsonclimatechange.com/ $>$.

${ }^{7}<$ http://www.revistaeconomistas.com/CEMadridRevista/indice/1109835/01052011/127-Mayo2011.html>.

8

$<$ http://premsa.gencat.cat/pres_fsvp/AppJava/notapremsavw/detall.do?id=165126\&idioma=0\&departame $\mathrm{nt}=101 \&$ canal $=102>$.
} 
$2011^{9}$ ) on conclou que el canvi climàtic és el responsable de la meitat de l'increment de les sequeres a la Mediterrània en els 10 últims episodis de sequera que s'han succeït els darrers 20 anys. El 50\% restant de responsabilitat en l'increment de freqüència de les sequeres a la nostra regió bioclimàtica es reparteix entre la variablitat natural del clima $i$ el patró cíclic de l'oscil·lació de l'Atlàntic Nord.

Cal destacar com l'increment de temperatura de les darreres dècades està provocant importants alteracions fenològiques en el cicle anual de moltes plantes $i$ animals. Les fulles de molts arbres, les flors de moltes plantes o molts insectes associats avancen la seva aparició entre 10 i 20 dies abans del que ho feien fa 30 a 50 anys. El desfasament del rellotge ecològic, que determina l'habilitat competitiva entre espècies, pot posar en risc la conservació de certs ecosistemes. El canvi climàtic comportarà canvis de caràcter hidrològic als rius, estanys, embassaments, zones humides, etc. A la vegada, les alteracions dels règims fluvials i/o de les característiques i la qualitat de l'aigua tindran una incidència tant directa com indirecta sobre l'estructura $\mathrm{i}$ el funcionament dels ecosistemes associats. Existeixen algunes constatacions de què ja s'han produït certs efectes sobre els organismes o el funcionament dels ecosistemes aquàtics degut a l'augment de temperatura, tant de l'aire com de l'aigua. Es poden assenyalar els canvis de comunitats planctòniques que s'han detectat en els sediments dels llacs de muntanya, la persistència de l'estratificació tèrmica i els seus efectes (anòxia) en embassaments situats en trams mitjans i baixos com és el cas de l'embassament de Sau, l'increment de les espècies més termòfiles de peixos dels rius i els canvis altitudinals d'algunes espècies (com la bagra que es troba a latituds superiors), canvis en l'emergència (més primerenca) d'alguns insectes aquàtics, com és el cas de les "palometes" del riu Ebre, o canvis en les pautes de distribució de diferents organismes marins i l'augment de les mortalitats en massa que es donen a la Mediterrània. Podem dir que l'evidència del canvi climàtic, almenys a petita escala, ja és palesa entre nosaltres.

Per això 1'Estratègia proposa una sèrie de mesures d'adaptació d'acord amb el grau de vulnerabilitat dels sectors $\mathrm{i}$ sistemes, $\mathrm{i}$ d'acord amb les actuacions que en matèria d'adaptació estan implantant altres nacions i estats del món traduïdes a l'especifitat del nostre territori. Arribats a aquest punt, paga la pena recordar quin és l'autèntic significat del concepte de desenvolupament sostenible; aquell que cobreix les necessitats del present sense comprometre la capacitat de les generacions futures per a cobrir les seves

\footnotetext{
${ }^{9}<$ http://journals.ametsoc.org/doi/abs/10.1175/JCLI-D-11-00296.1>.
} 
pròpies necessitats. L'avanç tecnològic permetrà ampliar les possibilitats actuals, però no es poden plantejar els horitzons futurs amb una confiança cega en aquestes possibilitats sense admetre les limitacions absolutes dels sistemes que ens proveeixen, així com les relacions i interconnexions (positives i negatives) entre ells. Sovint, desequilibris causats per un determinat element es manifesten a través d'efectes indirectes i traslladats en el temps. En l'actual conjuntura econòmica mundial podem tenir un bon exemple en l'evolució del binomi aigua i energia, cada vegada més interrelacionades. Millorar en l'eficiència de l'ús de l'aigua o cercar noves fonts de recurs més sostenibles des del punt de vista hidrològic pot revertir, en alguns casos, en majors despeses energètiques i majors impactes en altres àmbits i sectors.

Amb aquesta perspectiva, la implementació d'un model adaptatiu és l'única via que garanteix la provisió de serveis de qualitat a llarg termini i permet reduir la vulnerabilitat del sistema català davant el canvi climàtic. L'Estratègia Catalana d'Adaptació al Canvi Climàtic ha de promoure en el decurs de la seva progressiva implementació les fites següents:

— Promoció d'estructures institucionals més descentralitzades, on es fomenti la participació social

- Increment de la flexibilitat dels sistemes de dotació d'aigua, generació d'energia $\mathrm{i}$ infraestructures

- Desenvolupament de polítiques transversals i integrades entre els diferents àmbits i sectors

— Derivació dels excedents aconseguits mitjançant millores d'estalvi i eficiència, de l'aplicació de mesures de mercat i/o fonts alternatives de recursos a la progressiva restauració integral dels ecosistemes, en lloc de dirigir-se a crear noves demandes.

Tot això passa per entendre l'adaptació al canvi climàtic com un procés d'aprenentatge social orientat, principalment, a la transformació i adaptació dels agents socials (en lloc de la transformació del medi), i conferir a l'adaptació una posició molt més central i coherent que cal integrar en la resta d'altres polítiques com l'agricultura, l'energia, la planificació territorial o la conservació de la natura. Cal avançar en la millora del coneixement de les causes i els impactes del canvi climàtic, a la vegada que l'estratègia d'adaptació ha d'integrar tots aquests elements així com la necessitat d'un desenvolupament que faci més èmfasi en el mig i llarg termini que no pas en el curt. 


\section{ANTECEDENTS IMMEDIATS AL MÓN, EUROPA I ESPANYA}

L'adaptació al canvi climàtic és un àmbit de l'acció internacional contra l'escalfament global del planeta que va iniciar el seu camí l'any 1992. Tot seguit es fa una descripció cronològica dels antecedents fins a l'actualitat.

\section{Al món}

El Conveni marc de les Nacions Unides sobre el canvi climàtic (CMNUCC) ${ }^{10}$, aprovat el 1992, té com a objectiu l'estabilització de les concentracions de gasos amb efecte d'hivernacle (GEH) a l'atmosfera a un nivell que eviti interferències antropogèniques perilloses en el sistema climàtic. Aquest nivell s'hauria d'aconseguir dins un termini suficient perquè els ecosistemes s'adaptin naturalment al canvi climàtic, per assegurar que la producció d'aliments no en quedi amenaçada $i$ per permetre que el desenvolupament econòmic continuï de manera sostenible. En virtut del CMNUCC la comunitat mundial va adquirir un compromís per començar a treballar sobre les mesures per adaptar-se al canvi climàtic (article 4.1.b del conveni marc).

L'article desè del Protocol de Kyoto, signat l'11 de desembre de $1997^{11}$, estableix la formulació, execució, publicació i actualització periòdiques de programes nacionals i regionals que continguin mesures per mitigar el canvi climàtic i facilitar una bona adaptació al canvi climàtic. Aquests programes s'han d'ocupar dels sectors de l'energia, els transports i la indústria, així com de l'agricultura, l'àmbit forestal i la gestió de residus. Les tecnologies d'adaptació haurien de conduir a una millora de l'adaptació al canvi climàtic.

Al 2006, com a resultat de la Cimera de Nairobi (COP 12) ${ }^{12}$, s'adopten una sèrie de decisions i iniciatives noves per donar suport a països en vies de desenvolupament, que són els més vulnerables al canvi climàtic. Mentre que la Xina, els Estats Units d'Amèrica i Europa (UE-27) contribueixen amb el 24, 18 i 11\%, respectivament, d'emissions de GEH de tot el món, Àfrica només hi contribueix amb el 4\% i és la zona del planeta amb la vulnerabilitat més elevada. Per a reduir la vulnerabilitat, l'adaptació

\footnotetext{
${ }^{10}<$ http://unfecc.int/2860.php>

$11<$ http://unfccc.int/kyoto_protocol/items/2830.php $>$

$12<$ http://www.europarl.europa.eu/sides/getDoc.do?pubRef=-//EP//TEXT+TA+P6-TA-2006$0460+0+\mathrm{DOC}+\mathrm{XML}+\mathrm{V} 0 / / \mathrm{ES}>$.
} 
és vital per reduir els impactes del canvi climàtic que ja estan succeint ara i augmentar la resistència als impactes futurs. Una adaptació exitosa no només depèn dels governs, sinó també de la participació activa i sostinguda de les parts interessades (Programa de treball de Nairobi), incloses les organitzacions nacionals, regionals, multilaterals $\mathrm{i}$ internacionals, els sectors públic i privat (iniciativa del sector privat), la societat civil i altres parts interessades. L'objectiu del Programa de treball de Nairobi és ajudar tots els països a adaptar-se al canvi climàtic, reduint la vulnerabilitat als seus impactes negatius.

Els resultats del quart informe d'avaluació del canvi climàtic del Grup de Treball II de l'IPCC sobre impactes, adaptació i vulnerabilitat del canvi climàtic $(2007)^{13}$ exposa que una de les zones de la Terra més vulnerables al canvi climàtic serà la zona Mediterrània. Concretament, s'espera que al sud d'Europa empitjoraran les condicions ambientals (temperatures més altes i més sequeres) en una regió ja vulnerable a la variabilitat climàtica. En conseqüència, es reduirà la disponibilitat d'aigua, el potencial de generació hidroelèctrica, el turisme d'estiu i, en general, el rendiment dels cultius. S'esperen també més riscos per a la salut humana a causa d'una major freqüència d'onades de calor i incendis forestals.

A finals de 2007, la Cimera de Bali (COP13), va aprovar un pla d'acció (CMNUCC Decisió $1 /$ CP.13) on un dels quatre pilars és l'adaptació al canvi climàtic, tot i reflectint la necessitat que ja té gran part del món en adaptar-se al canvi climàtic. A Bali, les Parts també van donar llum verda a un fons d'adaptació, amb l'objectiu de finançar mesures d'adaptació en països en desenvolupament i començar a treballar a partir del 2009.

El 2009, en la Cimera de Copenhaguen (COP 15), Nacions Unides va incloure el reconeixement del paper dels governs subestatals o subnacionals tant en el plantejament com en la resolució en termes d'adaptació i mitigació de l'impacte del canvi climàtic, el que s'ha convingut a anomenar "l'esmena catalana" i que es féu efectiva gràcies a la Xarxa de Governs Regionals per al Desenvolupament Sostenible (NRG4SD).

L'informe de l'OCDE al novembre de 2010 sobre "Economic Aspects of adaptation to climate change" ofereix una avaluació crítica dels costos de l'adaptació i els beneficis en sectors claus sensibles al clima. Més enllà de l'estimació de costos, el debat es mou cap als potencials i les limitacions dels instruments econòmics i normatius a utilitzar per incentivar les mesures d'adaptació. L'informe també fa una crida a una plataforma

\footnotetext{
${ }^{13}<$ http://www.ipcc.ch/pdf/reports-nonUN-translations/catalan/ar4-syr-spm.pdf $>$
} 
d'instruments normatius per crear els incentius adequats per influir en la presa de decisions. Un dels grans reptes serà determinar els incentius i les estructures d'associació escaients per promoure l'adaptació.

Derivat del Conveni marc de les Nacions Unides sobre el canvi climàtic (CMNUCC) i del Programa de Treball de Nairobi, les Nacions Unides han publicat el 22 de novembre

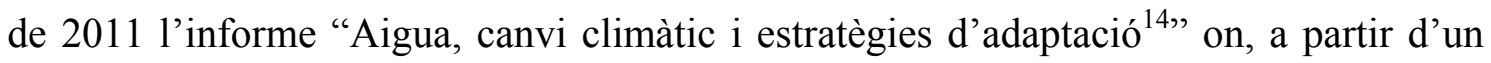
resum del coneixement a nivell mundial tant sobre les prognosis de variabilitat climàtica com sobre els impactes, conclou que i) cal fer més esforços en el desenvolupament de la regionalització climàtica; ii) cal introduir en l'anàlisi dels impactes en la gestió de l'aigua no només els derivats del canvi climàtic regionalitzat, sinó també els provocats per l'activitat humana; iii) la gestió integrada del cicle de l'aigua esdevé una poderosa arma d'adaptació als impactes.

\section{A Europa}

El Llibre verd d'Adaptació al Canvi Climàtic de l'any $2007^{15}$ identifica com una de les zones més vulnerables d'Europa al canvi climàtic tota la conca mediterrània degut a l'efecte combinat d'un augment de temperatura i una disminució de precipitacions en zones que ja pateixen estrès hídric. En concret preveu que a Catalunya la temperatura mitjana anual s'incrementi entre $+3,5^{\circ} \mathrm{C}$ i $+4^{\circ} \mathrm{C}$ i que la precipitació mitjana anual disminueixi majoritàriament al voltant d'un $20 \%$ d'aquí a finals de segle ${ }^{16}$. La UE centra l'acció en uns eixos principals, entre els quals es troben el de reduir la incertesa ampliant la base de coneixements mitjançant la investigació integrada sobre el clima, i la d'implicar a la societat, les empreses i el sector públic europeus en la preparació d'estratègies d'adaptació coordinades i globals.

El Llibre Blanc d'Adaptació al Canvi Climàtic comunicat l'abril del 2009 estableix un marc per a reduir la vulnerabilitat de la UE a l'impacte del canvi climàtic. Un dels seus nextoid=1a4cb75b297d6210VgnVCM1000008d0c1e0aRCRD\&vgnextchannel=1a4cb75b297d6210VgnV CM1000008d0c1e0aRCRD\&vgnextfmt=default\&newLang=ca_ES>

${ }^{16}$ Aquestes projeccions es basen en l'escenari A2 de l'IPCC, escenari on no es porta a terme cap acció per a reduir les emissions de GEH.
} 
objectius és la integració de l'adaptació en àmbits de política sectorial i ambiental, com per exemple els relacionats amb l'aigua, la biodiversitat, i l'eficiència en l'ús de recursos. Donat que el Llibre blanc reconeix que el limitat coneixement del que es disposa és un obstacle clau, adopta un enfocament gradual amb dues etapes diferenciades. En la primera fase (2009-2012) es pretén establir una base de coneixements més sòlida per preparar una estratègia global d'adaptació de la UE que es posarà en pràctica en la segona fase, que començarà el 2013 (vegeu més avall).

L'estudi Impacts of Europe's changing climate - 2008 Indicator-based Assessment ${ }^{17}$ de l'Agència Europea del Medi Ambient, el Joint Research Centre i l'Organització Mundial de la Salut preveu a la regió mediterrània un descens de la precipitació anual, descens en el cabal anual dels rius, més incendis forestals, cultius menys productius, increment de la demanda d'aigua del sector agrícola, major risc de desertificació, menys energia disponible per a les hidroelèctriques, increment de la mortalitat per onades de calor, més vectors de transmissió de malalties, menys turisme d'estiu i major risc de pèrdua de biodiversitat. L'informe indica com a principals reptes, entre d'altres, una millor comprensió dels aspectes socioeconòmics i institucionals de la vulnerabilitat i l'adaptació, la millora i coordinació de les anàlisis d'escenaris d'impactes i vulnerabilitat, la necessitat de més informació sobre bones pràctiques i com evitar la mala adaptació, i el desenvolupament de mecanismes d'intercanvi d'informació.

L'informe Climate Change Impacts in Europe. Final report of the PESETA research project $2009^{18}$ conclou que sense adaptació pública al canvi climàtic i si el clima de la dècada futura del 2080 succeís avui, les pèrdues anuals pel canvi climàtic en termes de pèrdua de PIB es produirien principalment en les regions del sud d'Europa. Aquestes pèrdues per a l'economia global de la UE oscil-larien entre els $20 \mathrm{i}$ els 65 mil milions d'euros en funció de l'evolució de la temperatura. Tenint en compte els patrons regionals de danys, l'àrea del sud d'Europa és la regió amb pèrdues més altes de benestar social, fins a 1'1,6\%. El benestar en aquesta regió es deteriorà profundament en l'escenari amb majors increments de temperatura. Totes les categories d'impacte són negatives, especialment els danys en el sector agrícola; pel que fa al turisme, s'espera una caiguda d'ingressos entorn els 5 mil milions d'euros / any.

\footnotetext{
${ }^{17}<\mathrm{http}: / /$ www.eea.europa.eu/publications/eea_report_2008_4>.

${ }^{18}<$ http://ftp.jrc.es/EURdoc/JRC55391.pdf>.
} 
L'informe El medi ambient a Europa. Estadi i perspectives 2010 (SOER 2010) ${ }^{19}$ de l'Agència Europea del Medi Ambient defineix adaptació com la capacitat d'ajust dels sistemes naturals o humans al canvis climàtic i als seus efectes actuals o previstos per tal de moderar els danys i/o explotar els beneficis. Aquest informe preveu que a la conca mediterrània l'augment de temperatura mitjana i la disminució de la disponibilitat d'aigua aguditzin la vulnerabilitat a sequeres, incendis forestals i onades de calor. Insta a què moltes de les iniciatives d'adaptació no haurien de portar-se a terme com accions independents, sinó com a part integrant d'unes mesures de reducció de riscos sectorials més àmplies. En aquest sentit, l'adaptació al canvi climàtic pot ajudar a augmentar la resiliència davant d'altres reptes ambientals i/o de canvi global. Tot i que els costos de l'adaptació a Europa poden ser potencialment molt elevats, la valoració de les opcions d'adaptació suggereix que les mesures d'adaptació oportunes tenen sentit econòmic, social i ambiental, ja que poden reduir els possibles danys de forma molt significativa $\mathrm{i}$ s'amortitzen amb escreix en comparació amb l'opció de la no acció.

La $\operatorname{COM}(2011) 21$ final $^{20}$ estableix que la utilització més eficient dels recursos serà clau per a progressar en la lluita contra el canvi climàtic i la protecció d'actius ecològics de gran valor, els serveis que presten i la qualitat de vida de les generacions actuals $i$ futures. La iniciativa perquè Europa utilitzi eficaçment els recursos pretén crear un marc polític destinat a potenciar el canvi cap a una economia eficient en l'ús dels recursos i de baixa emissió de carboni que ajudi a lluitar contra el canvi climàtic i limitar els impactes ambientals derivats de l'ús dels recursos.

El full de ruta energètic 2050 de la UE, la COM (2011) 885/2 21 més coneguda com Energy Roadmap 2050, té com a objectiu l'establiment d'un marc estable i coherent per a totes les iniciatives europees locals, nacionals o estatals de modernització $\mathrm{i}$ eficiència energètica. D'acord amb aquest full de ruta, la descarbonatació energètica és possible i menys costosa que seguir amb les polítiques actuals, extremadament dependents de l'exterior: el cost del sistema energètic al 2005 era del 10.5\% del PIB de la UE; al 2010 era del 14.6\%. En l'horitzó 2050, la descarbonatació faria disminuir la dependència exterior d'importació energètica entre un 35 i un $45 \%$.

\footnotetext{
$19<$ http://www.eea.europa.eu/soer>.

${ }^{20}$ Una Europa que utilitzi eficaçment els recursos - Iniciativa emblemàtica d'acord amb l'Estratègia Europea 2020.

${ }^{21}<$ http://ec.europa.eu/energy/energy2020/roadmap/index_en.htm>.
} 
La Comissió Europea va presentar el 29 d'abril de 2013 l'Estratègia d'adaptació al canvi climàtic a Europa ${ }^{22}$. En una doble sessió de matí i tarda, amb un discurs d'obertura impactant per part de la directora general del Clima de la $\mathrm{CE}$, la comissària danesa Connie Hedegaard, s'han explicat els treballs que des de l'Agència Europea de Medi Ambient (EEA, en anglès) s'han desenvolupat aquests darrers anys entorn la vulnerabilitat, els impactes i l'adaptació al canvi climàtic dels sistemes naturals i dels sectors socioeconòmics arreu d'Europa. Ara caldrà que el Parlament europeu aprovi l'Estratègia com a marc d'ajut i referència per als estats membres de la Unió i, també, de les nacions, regions $\mathrm{i}$ ens locals europeus. La vulnerabilitat als impactes del canvi climàtic, així com la identificació i magnitud d'aquests impactes en funció de les diverses regions biogeogràfiques europees (mediterrània, alpina, boreal, continental, atlàntica, etc.), depèn en gran mesura del grau d'exposició i sensibilitat tant física com socioeconòmica. L'adaptació, doncs, necessita d'estratègies locals (ciutats) i nacionals per afrontar, amb èxit, el desafiament que suposa el canvi climàtic.

Lluny de ser una mera orientació per als Estats membres, l'Estratègia europea marca deures i dates límit per fer aquests deures. Així, per exemple, per a l'any 2017 tots els estats membres hauran hagut d'adoptar una estratègia d'adaptació; per a l'any 2020 són les ciutats de més de 150.000 habitants les cridades a adoptar-les. S'estableix que el programa Life+ és un instrument excel-lent per afavorir l'intercanvi d'experiències en adaptació entre sectors $\mathrm{i}$ territoris, o bé que la plataforma Climate-ADAPT ${ }^{23}$ ha de permetre escurçar, cada vegada més, els buits de coneixement. Reconeix, també, que si bé l'esforç més important en el monitoratge del canvi climàtic ha estat adreçat a l'avaluació dels impactes, cal decididament emprendre també el monitoratge de la bondat de les mesures d'adaptació ja implantades o que calgui implantar, atès que és necessari aquest coneixement per a l'avaluació de les polítiques arreu d'Europa.

L'adaptació al canvi climàtic, com la mitigació dels gasos amb efecte d'hivernacle, no és només un problema mediambiental, sinó també un problema de dimensió econòmica. Per tant, ha de ser tractat conjuntament tant pels responsables ambientals com pels responsables de les polítiques econòmiques. De fet, el cost de la no adaptació als impactes del canvi climàtic a Europa ha estat avaluat entorn dels 100 mil milions

\footnotetext{
${ }^{22}<\mathrm{http}: / /$ ec.europa.eu/clima/policies/adaptation/what/documentation_en.htm>.

${ }^{23}<$ http://climate-adapt.eea.europa.eu $>$.
} 
d'euros l'any 2020. Aquesta xifra gegantina és la valoració econòmica feta per l'EEA entorn de les inundacions, l'afecció a les zones costaneres, l'energia necessària per a la refrigeració i la mortalitat deguda a les onades de calor. Per cada euro que s'inverteixi ara en accions preventives davant les inundacions, s'estalvien fins a sis euros en les mesures correctives adreçades a arranjar els danys ocasionats per les riuades.

La gestió dels riscs derivats del canvi climàtic implica agrupar els esforços de la mitigació amb l'adaptació, atès que els resultats d'aquests esforços, avui, determinaran, demà, el grau d'adaptació necessari. Cal celebrar especialment aquesta afirmació continguda en el document de treball de la Comissió europea, atès que l'Estratègia Catalana d'Adaptació al Canvi Climàtic (ESCACC) considera que, precisament per aquesta raó, la mitigació és una mesura precautòria de l'adaptació als impactes del canvi climàtic. De la mateixa manera que l'ESCACC té com a objectiu estratègic esdevenir menys vulnerables als impactes del canvi climàtic, l'Estratègia europea vol contribuir d'una manera efectiva a construir una Europa més resilient al clima. Dues maneres diferents d'expressar una finalitat comuna i idèntica. Per aconseguir-ho cal fomentar el coneixement, cal redactar i implementar estratègies locals, nacionals i regionals d'adaptació, així com desenvolupar la integració de l'adaptació tant en les polítiques sectorials, com en el finançament dels diversos programes europeus i en els sectors més vulnerables.

\section{A Espanya}

El Plan nacional de adaptación al cambio climático (PNACC, 2007) ${ }^{24}$ s'elabora com a marc per a la coordinació entre administracions públiques per a les activitats d'avaluació d'impactes, vulnerabilitat i adaptació al canvi climàtic. Entre els seus objectius específics inicials hi ha el de desenvolupar i aplicar mètodes $\mathrm{i}$ eines per avaluar els impactes, la vulnerabilitat i l'adaptació al canvi climàtic en diferents sectors socioeconòmics i sistemes ecològics a Espanya, i el de promoure la participació entre tots els agents implicats en els diferents sectors/sistemes, amb objecte d'integrar en les polítiques sectorials l'adaptació al canvi climàtic. El Plan preveu el desenvolupament de dos programes de treball.

\footnotetext{
${ }^{24}<$ http://www.magrama.gob.es/es/cambio-climatico/temas/impactos-vulnerabilidad-y-adaptacion/plannacional-adaptacion-cambio-climatico>.
} 
El Primer Programa de treball recull les activitats inicials que es desenvoluparan en determinats sectors socioeconòmics i sistemes ecològics espanyols. Els sectors que considera d'elevada prioritat són: la generació d'escenaris climàtics regionals i l'avaluació de l'impacte del canvi climàtic en els recursos hídrics, la biodiversitat i les zones costaneres. Els resultats que es derivin d'aquestes primeres activitats i projectes serviran de base per a posteriors avaluacions d'impactes, i proporcionaran la informació necessària per dinamitzar processos participatius dels responsables i principals implicats en cada sector, i per definir les opcions d'adaptació possibles davant el canvi climàtic.

El Segon Programa de treball gira entorn a quatre eixos: l'avaluació sectorial d'impactes, vulnerabilitat i adaptació al canvi climàtic, la integració de l'adaptació al canvi climàtic en la normativa sectorial, la mobilització dels actors claus (públics i privats) que hauran de participar activament en la identificació de mesures d'adaptació al canvi climàtic, i l'establiment d'un sistema d'indicadors dels impactes i l'adaptació en tots els sectors. Cal valorar positivament els seminaris sectorials que des de l'Oficina Española del Cambio Climático (OECC) s'organitzen amb centres de recerca, administracions i gestors pel que suposen de posada en comú i orientacions en adaptació en boscos, biodiversitat, regionalització climàtica, salut, etc. És de destacar la publicació Evaluación del impacto del cambio climático en los recursos hídricos en régimen natural $^{25}$ (juny 2011), realitzada pel Centro de Estudios y Experimentación de Obras Públicas (CEDEX) i que es basa en les projeccions climàtiques regionalitzades preparades per la Agencia Estatal de Meteorología (AEMET).

\section{ANTECEDENTS I SITUACIÓ A CATALUNYA: L'APROVACIÓ DE L'ESTRATÈGIA CATALANA D'ADAPTACIÓ I LA LLEI DE CANVI CLIMÀTIC}

Catalunya ha anat fent els deures a mida que el context internacional avançava. Així, ja el Pla marc de mitigació del canvi climàtic a Catalunya 2008-2012 ${ }^{26}$, tot i que el seu objectiu no és fer una anàlisi dels impactes del canvi climàtic ni incorporar mesures

\footnotetext{
${ }^{25}<$ http://www.magrama.gob.es/es/agua/temas/planificacionhidrologica/resumenejecutivodef7_con_web_tcm7-165447.pdf $>$.

26

$<$ http://www20.gencat.cat/docs/Sala\%20de\%20Premsa/Documents/Arxius/com_govern_admin.acordsGo vern.ca_ES.Pla\%20canvi\%20climatic1222778578559.pdf $>$.
} 
d'adaptació, sí que proposa que, seguint la línia d'acció de la UE i de la comunitat internacional, primer es defineixin les polítiques de mitigació (tal i com fa el propi pla) per tal d'abordar de manera immediata les anàlisis sectorials i biofísiques que permetin definir una política efectiva d'adaptació.

Dos anys més tard, el Segon Informe sobre el canvi climàtic a Catalunya $(2010)^{27}$ fa una aproximació a escala territorial dels escenaris de futur i les conseqüències del canvi climàtic. Una bona part de l'estudi té com a principal objectiu analitzar els impactes i les possibles mesures d'adaptació en diferents sectors d'activitat econòmica. Hi ha també un apartat que es dedica a analitzar estructuralment la comunitat científica que aprofundeix en el coneixement del canvi climàtic i la seva evolució durant els darrers anys.

El mateix any 2010, el Pla de gestió del districte de conca fluvial de Catalunya ${ }^{28}$ no considera, sota condicions de canvi climàtic, canvis en les aportacions mitjanes en l'horitzó 2015, davant les incerteses encara existents i el fet que la pròpia irregularitat del règim històric és molt més elevada que els possibles canvis que es podrien arribar a donar en aquest horitzó. En canvi, per a l'escenari 2027 i a nivell d'anàlisi de valoració dels recursos disponibles, considera una reducció mitjana de les aportacions que pot ascendir a un màxim del 5\%, més intensa en períodes secs i als rius més irregulars. Així, als mesos d'estiu la reducció anual es pot doblar i als anys secs pot arribar a ser un 20\% superior. Per contra, als anys humits es poden arribar a donar increments d'aportació de fins al 5\%. Més enllà del 2070 amb increments de temperatura que podrien arribar a 3-4 ${ }^{\circ} \mathrm{C}$, amb disminucions de precipitació d'entre el -10 i el $-16 \%$, la reducció mitjana d'aportacions arribaria a valors de l'ordre del -16 al -28\%. Pel que fa a la component subterrània del cicle hidrològic, s'estima una reducció mitjana de la recàrrega d'aigües subterrànies de l'ordre del 20\% per al període 2070-2100. D'altra banda, i per aquest mateix període, hom preveu que s'aguditzarà el règim hidrològic estacional, amb una marcada reducció d'aportacions a l'estiu (fins a -40\%) que, en alguns casos, es podria compensar parcialment amb certs increments a l'hivern $(+10 \%)$.

27

$<$ http://www15.gencat.cat/cads/AppPHP/index.php?option $=$ com_content\&task $=$ view\&id=736\&Itemid=1 $60 \&$ lang $=\mathrm{ca}>$.

$28<$ http://aca-

web.gencat.cat/aca/appmanager/aca/aca?_nfpb=true\&_pageLabel=P29600129321280749434777\&_nfls= false $>$. 
L'any 2012, els resultats de l'esforç realitzat conjuntament entre el Servei Meteorològic de Catalunya i el Barcelona Supercomputing Center - Centre Nacional de Supercomputació (BSC-CNS) sobre la generació d'escenaris climàtics regionalitzats per al període 2001-2050 han estat cabdals per a poder redactar i aprovar l'Estratègia Catalana d'Adaptació al Canvi Climàtic 2013-2020 (ESCACC). Aquests resultats ${ }^{29}$ són els següents:

- Augment significatiu i robust de la temperatura mitjana anual a Catalunya durant el període 2001-2050 respecte de 1971-2000, amb una tendència mitjana entre $+0,8{ }^{\circ} \mathrm{C} \mathrm{i}+1,8{ }^{\circ} \mathrm{C}$. A més, l'increment de temperatura seria més important en el període 2031-2050 que en el període 2011-2030.

— Aquest augment de la temperatura mitjana anual segueix un gradient latitudinal i altitudinal, de manera que el màxim increment s'assoleix al Pirineu Occidental (al voltant de $+2,0{ }^{\circ} \mathrm{C}$ ) i el mínim s'obté al litoral sud (al voltant de $+1,0{ }^{\circ} \mathrm{C}$ ).

- A escala estacional, l'augment més marcat s'obté a l'estiu a determinades zones del Pirineu (superior a $+2,5^{\circ} \mathrm{C}$ ). A Catalunya, en general, la variació màxima de temperatura s'assoleix a l'estiu i la variació mínima seria a l'hivern, mentre que la tardor i la primavera són estacions intermèdies.

- Augmenta la probabilitat d'ocurrència dels mesos molt càlids i varia poc la dels mesos freds.

— Es projecta un augment del nombre de nits tropicals (dies amb temperatura mínima superior a $20^{\circ} \mathrm{C}$ ) durant el període 2001-2050, que podria arribar a un $+7 \%$ superior al nombre mitjà del període 1971-2000; aquest augment es notaria especialment a la zona Litoral i Prelitoral (amb màxims entre 20 i 30 nits tropicals més a l'any). D'altra banda, hi hauria una disminució d'un 5\% del nombre de dies de glaçada (dies amb temperatura mínima igual o inferior a $0{ }^{\circ} \mathrm{C}$ ), sobretot a l'interior del país i al Pirineu (en aquesta darrera zona, la disminució màxima estaria entre 30 i 40 dies de glaçada menys a l'any).

29

$<$ http://www15.gencat.cat/cads/AppPHP/images/stories/ambits_de_treball/2n_informe_cc_a_catalunya/tr obada_avellanes_juny_2012/3-jordi_cunillera.pdf > . 
— Les tendències projectades per a la precipitació mitjana anual presenten més incerteses, i depenen força de la simulació considerada i de la zona geogràfica. El rang de variació més probable és entre $-10 \% \mathrm{i}+5 \%$.

- La variabilitat interanual de la precipitació durant el període 2001-2050 seria més elevada que la registrada durant 1971-2000, especialment a la zona litoralprelitoral.

- Malgrat la incertesa en aquesta variable, es pot dir que la precipitació mitjana anual tendeix a disminuir a gran part del territori, especialment al Pirineu Occidental, però al litoral podria arribar a augmentar, sobretot al litoral nord.

— Existeixen grans diferències a escala estacional segons l'escenari d'emissions utilitzat, però la majoria de simulacions proporcionen un augment de la precipitació mitjana d'hivern (sobretot al litoral) i una disminució a la primavera; l'estiu i la tardor presenten més incertesa.

- Es projecta per al conjunt de Catalunya un augment en la probabilitat d'ocurrència d'episodis de precipitació extrema (superior als $200 \mathrm{~mm}$ en 24 hores), malgrat aquesta probabilitat continuaria essent baixa.

— Els índexs climàtics relacionats amb la precipitació no mostren tendències molt clares, però es pot destacar un augment $(+7,6 \%$ de mitjana) de la longitud màxima de la ratxa seca (LMRS, nombre màxim de dies consecutius en un any amb precipitació inferior a 1,0 mm); es passaria d'un valor mitjà de 66 dies per al període 1971-2000 a un valor mitjà de 71 dies per al període 2001-2050. Aquest augment seria més marcat a la zona Litoral i Prelitoral, amb valors màxims de l'index LMRS per al període 20012050 força superiors als 100 dies.

- Disminució de la velocitat del vent a 10 metres, amb un major rang de variabilitat interanual, un augment de la freqüència dels mesos poc ventosos i una disminució de la dels mesos molt ventosos.

L'Estratègia Catalana d'Adaptació al Canvi Climàtic 2013-2020 (ESCACC) és l'instrument que ha de permetre esdevenir menys vulnerables als impactes del canvi climàtic a Catalunya. Del total dels 63 impactes descrits a l'ESCACC, 32 són impactes ja observats, un clar indicador que el canvi climàtic a Catalunya, lluny de ser una quimera, és una realitat contrastable. 
Les principals conclusions contingudes a la diagnosi de l'ESCACC són:

— El Pirineu i el litoral, i dins aquest àmbit especialment el delta de l'Ebre, són les àrees geogràfiques que presenten una major vulnerabilitat. El primer territori estarà afectat pels augments de temperatura mitjana previstos de fins a $+4,6{ }^{\circ} \mathrm{C}$ a finals de segle (escenari A2). Pel que fa al litoral, l'increment del nivell del mar — significatiu al delta de l'Ebre-, l'increment de fenòmens meteorològics extrems, el canvi en el règim d'onatge, així com la concentració de població i infraestructures en aquesta àrea geogràfica, són factors que accentuen la vulnerabilitat de l'àrea costanera.

- L'aigua és el sistema més vulnerable als impactes climàtics observats i futurs a Catalunya. De les afectacions sobre l'aigua i la seva gestió en depenen molts dels impactes derivats sobre altres sectors i sistemes. La diagnosi tècnica efectuada apunta clarament a la disminució de la disponibilitat d'aigua, les seves alteracions fisicoquímiques i les alteracions en masses d'aigua subterrànies així com en els règims estacionals.

- Agricultura i ramaderia: sector molt vulnerable als impactes climàtics ja observats i futurs sobre la producció agrícola de cereals, fruita dolça, oliveres o vinya. La menor disponibilitat d'aigua aconsella l'adaptació de les polítiques agràries cap a l'impuls de productes pròxims (hortes en zona costanera) i d'alta qualitat (com la vinya i l'olivera).

- Biodiversitat: sistema molt vulnerable per les afectacions ja observades en els canvis fenològics, migracions i composició d'espècies i canvis funcionals.

- Boscos (gestió forestal): sistema molt vulnerable amb afectacions ja observades com els canvis en la distribució de les espècies, la major aridesa i erosió de sòls i l'augment del risc d'incendis forestals.

- Mobilitat i infraestructures de transport: sistema molt vulnerable als impactes climàtics associats a fenòmens meteorològics extrems. Les afectacions sobre el transport viari, ferroviari o sobre les infraestructures costaneres comporten importants implicacions econòmiques i socials.

- Pesca i aqüicultura: el sector, ja sotmès a fortes pressions derivades del canvi global, esdevindrà també vulnerable al canvi climàtic, observant ja alteracions en la trofodinàmica i en l'entorn biològic. 
- Salut: sector molt vulnerable al canvi climàtic amb episodis extrems ja observats a Catalunya com les onades de calor, afectacions sobre la qualitat de l'aire o els transtorns al·lèrgens.

- Sector energètic: sector molt vulnerable als impactes climàtics associats a fenòmens meteorològics extrems. Les afectacions sobre les instal·lacions de generació, transport i distribució elèctriques comporten importants implicacions econòmiques $\mathrm{i}$ socials ja conegudes a Catalunya.

- Turisme: sector molt vulnerable als impactes climàtics amb variacions del confort tèrmic, afectacions de la cota de neu o disponibilitat de recursos hídrics ja observats a Catalunya.

La diagnosi efectuada a cinc sectors clau pel que fa al seu pes en l'economia, d'acord amb la realitat i el coneixement actual de l'adaptació al canvi climàtic a Catalunya, determina:

- La intervenció pública en les polítiques d'adaptació en la perspectiva temporal a llarg termini és clau.

- En el context empresarial, ni per als sectors que en resultaran més afectats, no hi ha una perspectiva temporal que possibiliti un ritme adequat d'adopció de mesures d'adaptació al canvi climàtic.

— El sector públic ha de proveir un coneixement adequat dels impactes i de les millors estratègies adaptatives, $i$ ha de crear un marc normatiu $i d$ 'incentius que estimuli la consideració del mitjà i llarg termini en la presa actual de decisions.

L'ESCACC planteja fins a 182 mesures d'adaptació als impactes del canvi climàtic, bé sigui mitjançant la generació i transferència del coneixement sobre adaptació, bé sigui mitjançant l'augment de la capacitat adaptativa dels sistemes i sectors analitzats. D’aquestes 182 mesures 30 són genèriques, mentre que les 152 restants són específiques per als sectors socioeconòmics i sistemes naturals.

La primera de les mesures genèriques establertes a l'ESCACC és que Catalunya hauria de plantejar-se també la necessitat de redactar i aprovar una llei sobre el canvi climàtic. Una llei catalana sobre el canvi climàtic hauria de permetre: i) fer més sòlid l'anclatge competencial, davant d'una interpretació restrictiva del paper de les comunitats autònomes en matèria de canvi climàtic per part de l'Estat; ii) establir uns nivells de 
referència propis que permetessin analitzar el nivell d'esforç que ha de realitzar el nostre país per acomplir amb els compromisos d'abast mundial i europeu; iii) la coordinació amb el món local atès que les administracions locals tenen també un important paper a desenvolupar en matèria d'aplicació de polítiques efectives de canvi climàtic; iv) reforçar el posicionament internacional de Catalunya, reconegut en els acords aprovats a la cimera del canvi climàtic de Cancún el 2010; v) introduir incentius que facilitin el desenvolupament d'actuacions de mitigació i d'adaptació per crear els estímuls que, especialment en els moments inicials, contribueixin a superar les barreres que obstaculitzin el seu avanç; vi) major coordinació intersectorial atès que són molts els àmbits competencials que es veuen afectats pel fenomen del canvi climàtic; i vii) reforçar el vincle entre la mitigació i l'adaptació, atorgant una visió més holística i integradora de les polítiques d'acció contra el canvi climàtic.

Sortosament, el Govern de la Generalitat de Catalunya va aprovar la memòria inicial justificativa de la futura Llei del Canvi Climàtic ${ }^{30}$ el juny del 2012, amb l'objectiu que el nostre Parlament pugui aprovar-la en aquesta legislatura.

\footnotetext{
${ }^{30}<$ http://premsa.gencat.cat/pres_fsvp/AppJava/notapremsavw/detall.do?id=152921>.
} 